\title{
SMEs and Family Smes: Specificities from the Portuguese Socio-Business Context
}

\author{
Ana Paula Marques ${ }^{1}$ \\ Department of Sociology at the University of Minho \\ Interdisciplinary Centre of Social Sciences (UMinho Pole) \\ Ana Isabel Couto \\ Polytechnic Institute of Porto (ISCAP-IPP and ESE-IPP) \\ Institute of Sociology at the University of Porto (IS-UP)
}

Abstract

The composition of the corporate structure constitutes a relevant indicator of the entrepreneurial and economic dynamism of a certain country or territory. In contrast to past estimates over the past 45 years, the importance of small or very small scale entreprises has been steadily decreasing in the Portuguese business universe. The Portuguese socio-entrepreneurial fabric is predominantly constituted by small and very small scale businesses (micro companies): in 2015, 99,9\% of the non financial Portuguese sector were SME [Small and Medium-size companies], and the micro scale companies represented around $96 \%$ of the total number of SME. In this context, family businesses acquire greater relevance due to/for the estimated weight they have on the economy (between $70 \%$ to $80 \%$ of the SME, also including great companies quoted on the stock exchange markets), on the creation of jopbs and on the role they play in the local development. Notwithstanding, there still is a significant unawareness of the business layouts of the family companies. In effect, these tend to be heterogeneousin terms of size, activity sector and degree of professionalization of the respective government models and human resources.. The ongoing project, "Roadmap for the Portuguese family businesses" (2016-2018), financed by the NORTE 2020/ FEDER has as a central goal to contribute to a better acknowledgement and assessment of the impact of family companies in the northern region, as far as the local, national and international economy is concerned. For this purpose, it will build a database of the Portuguese northern region, mapping all the companies that present the layout of a family business and apply an online survey, combined with in-depth interviews to the various types and segments of family businesses, reinforcing their economic and social roles.

Keywords: SMEs and family businesses, North of Portugal, Segments, Database

\section{Introduction}

The fact that this specificity of the Portuguese business and employment context is relatively absent from the social sciences research agenda is all the more surprising, and as such generating more interest, when one considers the great relevance that SMEs have in the Portuguese social and economic fabric, in addition to being one of the main sources for jobs in the non-financial private sector in Portugal in recent decades.

Furthermore, family-owned businesses, which are overwhelmingly SMEs, even though they may comprise large economic groups, are arguably important agents for the creation of wealth, employment and territorial and social cohesion. They are a substantive part of the dynamism of the national and European economies, accounting for over $60 \%$ of enterprises in various sectors of activities. In Portugal, it is estimated that $70 \%$ to $80 \%$ of national businesses are family owned, taking

\footnotetext{
1 Interdisciplinary Center of Social Sciences - University of Minho, UID / SOC / 04 647/2013 with the financial support of FCT / MEC through National funds and if applicable co-financed by the ERDF Scope of the Agreement PT2020 partnership.
} 
up $50 \%$ of the labour force and accounting for $2 / 3$ of the GDP. In fact, according to the Portuguese Family Businesses Association [Associação Empresas Familiares], in Portugal "it is estimated that $70 \%$ of all businesses have a family structure and ownership" (online document 27-05-2015). However, one of the major problems family businesses have to face is the lack of institutional visibility for their contribution, namely: 1) in economic terms, in the wealth and added value creation production chain, particularly with regard to the take-up of technology and knowledge transfer (mostly through start-ups and entrepreneurial activities connected with the R\&D and innovation sectors); ii) in terms of job creation and consolidation throughout the business cycle; iii) in terms of organisation and governance of family businesses; iv) in terms of the ability to attract and retain human resources.

It is equally important to be aware of other reasons that explain why it is important to contribute to improving knowledge of family businesses as a major business structure in a competitive world both at a local and global level.

In fact, as they are sectors that have a strong family presence due to the proximity of the types of goods and services provided, family businesses have a certain stability (resilience) and tend to take on a significant local/regional scope. It is, thus, worth underlining the special connection these businesses have with the local communities, namely by contributing to retaining the population in the regions they are located in. In many local communities, family businesses may serve as a "buffer" in economic crisis situations due to their higher stability over time.

At the same time, these family businesses have to deal with a kind of invisibility/depreciation when it comes to their potential to transform the patterns of industrial specialisation, innovation and technology and knowledge transfer. That is to say, their economic contribution and added value are unknown, particularly in terms of the take-up of technology and knowledge transfer (mostly through start-ups and entrepreneurial activities connected with the R\&D and innovation sectors).

In this context, one of the major problems facing family businesses Portugal (and in Europe) is the lack of institutional visibility, where there are no accurate and updated official statistics on this sector of the economy. It is still not possible to determine exactly how many SMEs are, in fact, family businesses and when that is the case, their dynamics and (potential) contribution to the national and international markets remain unknown.

In the first point of this article, a statistical snapshot of the Portuguese social and business fabric will be drawn up. To that end, a number of variables and current key indicators will be considered: distribution of enterprises in the Portuguese business sector according to their size, employment figures and turnover for each size-class, and geographical distribution, with particular emphasis on the North of Portugal.

In the second point, we will discuss the importance of family businesses as the main business structure in a competitive world both on a local and global scale, underlining their significant role in creating productive value and employment impacting on local communities. Furthermore, we will address the uniqueness of family businesses arising from relations that play out at three levels: ownership, business and family.

In the third and final point of the article, the ongoing project "A Roadmap for Portuguese Family Businesses" ["Roadmap para Empresas Familiares Portuguesas"] will be presented. It is a project funded within the framework of NORTE-02-0853FEDER-000018 and is headed by the Interdisciplinary Centre of Social Sciences - University of Minho (Portugal) [Centro Interdisciplinar de Ciências Sociais - Universidade do Minho] in co-promotion with the Portuguese Entrepreneurial Association (AEP). The project focuses on the role and impact of family businesses in the economy and the main challenges arising therefrom, with a view to establishing a relevant agenda in terms of increasing visibility by producing not only accurate and reliable statistics but also knowledge that may aid policy decision making.

One of the aims of this article , and of the broader project it is part of, is , thus, to contribute to improving the knowledge of this particular empirical field, which is of unquestionable importance in the Portuguese social and business fabric: the SME and, in particular, family SMEs. 


\section{A snapshot of the Portuguese private social and business fabric}

\section{The makeup of the business fabric: the quantitative importance of SMEs}

When seeking to analyse the social and business fabric of a given country or territory one has to consider a key analysis indicator: the size structure of the companies that comprise it. In fact, as suggested by Freire "despite their simplicity and concreteness, the "size" (or size structure) of firms and the tallying of their number at a given time in a given territory are two basic operative concepts of economic sociology. The latter indicates the number of economic agents that at their own risk operate in the market as firms selling a certain product, while the scale of the firm (regardless of how it is run) is always a crucial economic power factor" (Freire, 2008:55).

The makeup of the business structure has thus come to be regarded as a relevant indicator of a country's business and economic dynamism. As far as the Portuguese context is concerned, and in contrast to previous projections, in the last forty years the weight of small or very small businesses has been increasing in the domestic business world (idem: 54).

According to INE (National Statistics Institute) data and previous studies (Guerreiro, 1996; Guerreiro et al., 2000; Freire, 2008; Couto, 2013), the Portuguese social and business fabric is mostly made up of small and very small businesses (also known as micro enterprises).

As can be seen in Table 1, this is a pattern which has remained stable over the years, as they account on average , for 95.7\% of all businesses in Portugal between 2004 and 2011. Small businesses come next, making up on average 3.7\% while medium-sized companies account for $0.5 \%$. Large companies represent a mere $0.1 \%$ of national businesses operating in the non-financial and private sector in the country.

The most recent data published by INE allows one to ascertain that, in 2015, 99.9\% of the businesses in the Portuguese non-financial sector are SMEs (encompassing, thus, the micro, small and medium businesses). Micro enterprises predominate, making up around $96 \%$ of the total amount of SMEs. In contrast, large companies account for merely $0.1 \%$. (Figure 1).

Table 1. Number of micro, small, medium-sized and large enterprises in the business sector in Portugal between 2004 and 2011 (\% in rows)

\begin{tabular}{llllllllll}
\hline Size & $\begin{array}{l}\text { Micro } \\
(<10 \text { workers })\end{array}$ & & $\begin{array}{l}\text { Small } \\
(10-49 \text { workers })\end{array}$ & & $\begin{array}{l}\text { Medium-sized } \\
(50-249 \text { workers })\end{array}$ & $\begin{array}{l}\text { Large } \\
(\geq 250 \text { workers })\end{array}$ & Total \\
\hline Year & $\mathrm{n}$ & $\%$ & $\mathrm{n}$ & $\%$ & $\mathrm{n}$ & $\%$ & $\mathrm{n}$ & $\%$ & $\mathrm{~N}$ \\
\hline 2004 & 1.035 .694 & 95,5 & 42.352 & 3,9 & 5.997 & 0,6 & 885 & 0,1 & 1.084 .928 \\
\hline 2005 & 1.072 .267 & 95,6 & 42.439 & 3,8 & 5.953 & 0,5 & 870 & 0,1 & 1.121 .529 \\
\hline 2006 & 1.092 .948 & 95,6 & 43.754 & 3,8 & 6.055 & 0,5 & 891 & 0,1 & 1.143 .648 \\
\hline 2007 & 1.154 .444 & 95,7 & 44.524 & 3,7 & 6.223 & 0,5 & 925 & 0,1 & 1.206 .116 \\
\hline 2008 & 1.183 .276 & 95,8 & 44.610 & 3,6 & 6.276 & 0,5 & 931 & 0,1 & 1.235 .093 \\
\hline 2009 & 1.149 .325 & 95,9 & 42.590 & 3,6 & 5.970 & 0,5 & 896 & 0,1 & 1.198 .781 \\
\hline 2010 & 1.096 .155 & 95,8 & 41.308 & 3,6 & 5.792 & 0,5 & 895 & 0,1 & 1.144 .150 \\
\hline 2011 & 1.066 .065 & 95,9 & 39.400 & 3,5 & 5.637 & 0,5 & 898 & 0,1 & 1.112 .000 \\
\hline average $\%$ & - & 95,7 & - & 3,7 & - & 0,5 & - & 0,1 & - \\
\hline
\end{tabular}

Source: INE, Sistema de Contas Integradas das Empresas, 2013

Employment structure and turnover generated by the business sector: the contribution of SMEs 
SMEs are the major source of job creation in the Portuguese non-financial and private sector. In fact, in $2015,79.3 \%$ of the jobs generated by businesses come from SMEs, with the microbusinesses accounting for $46.4 \%$ (figure 1).

Concerning the contribution of SMEs to the total turnover of the country's business sector, micro enterprises together with small and medium-sized ones account for $53.8 \%$ of the turnover. It should be mentioned, however, that the contribution of micro enterprises in this respect is low, representing only $17.2 \%$ of the turnover. Therefore, despite comprising the overwhelming majority of Portuguese businesses $(96.2 \%)$, the turnover of these enterprises is low. Conversely, the large companies, while lower in number, account for almost $47 \%$ of the total turnover of the national business sector, which is, to some extent, to be expected. (Table 1 and Figure 1).

Figure 1. Main indicators of enterprises in the private business sector, by size, in 2015. (\%)

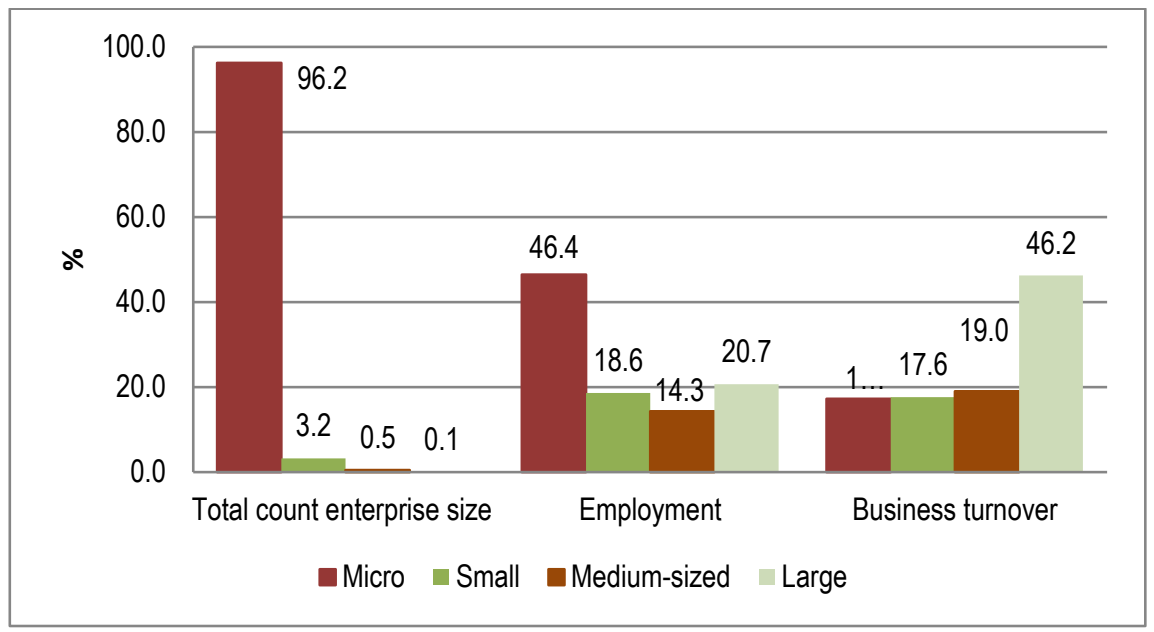

Source: INE, Sistema de Contas Integradas das Empresas, 2015

These specificities of the Portuguese social and business fabric, especially the high predominance of small and very small enterprises, are perceived as being the result of a convergence of a variety of socioeconomic phenomena occurring in Portuguese society in the last few decades. In this regard, Freire highlights "the entropy and fragmentation affecting giant enterprises (namely industrial ones); a higher business specialisation, often associated to "streamlining" processes; the appetite the Portuguese have for self-employment; government support and promotion of "self-employment" as an "active employment measure"; "fake companies" (existing only on paper) set up to obtain advantages for their founders (accounting, managerial, tax, etc.); companies ceasing operations rather than being formally dissolved as it is too expensive and difficult; and possibly other reasons as well" (Freire, 2008:56).

\section{Regional breakdown of the Portuguese business fabric}

Regarding the breakdown of enterprises by region, the INE data for 2015 confirms that "similarly to many other matters, the regional geography of the enterprises is quite uneven throughout the country" (Freire, 2008:58). In general terms, the North and Lisbon are the regions where there is a higher number of enterprises, in contrast with the Alentejo, the Algarve and the autonomous regions of the Azores and Madeira, where they are substantially fewer. The pace of urbanisation and the areas of high population concentration are some of the reasons put forward to explain the distribution breakdown and the territorial concentration of the Portuguese business fabric. 
In terms of the geographical breakdown of the businesses by size, $32.2 \%$ of the micro enterprises registered in Portugal in 2015 are located in the North, $29.4 \%$ in the Lisbon region and $21.7 \%$ in the Centro region. In the North, $12.6 \%$ of the microenterprises are in the Greater Porto area, contrasting with other areas in the region, such as the Douro, with only $1.7 \%$ of the total number of micro enterprises. This testifies to the heterogeneity of the business fabric in this region, on the one hand, and to the fact that the North is not a single and monolithic region as far as business activity is concerned. The Greater Lisbon sub-region has the highest number of micro enterprises in 2015 , with $22.8 \%$ of the total number of businesses of this size. (Table and Figure 2).

Figure 2. Breakdown of enterprise size -classes by region ( NUT II ) in 2015 (\% in columns)

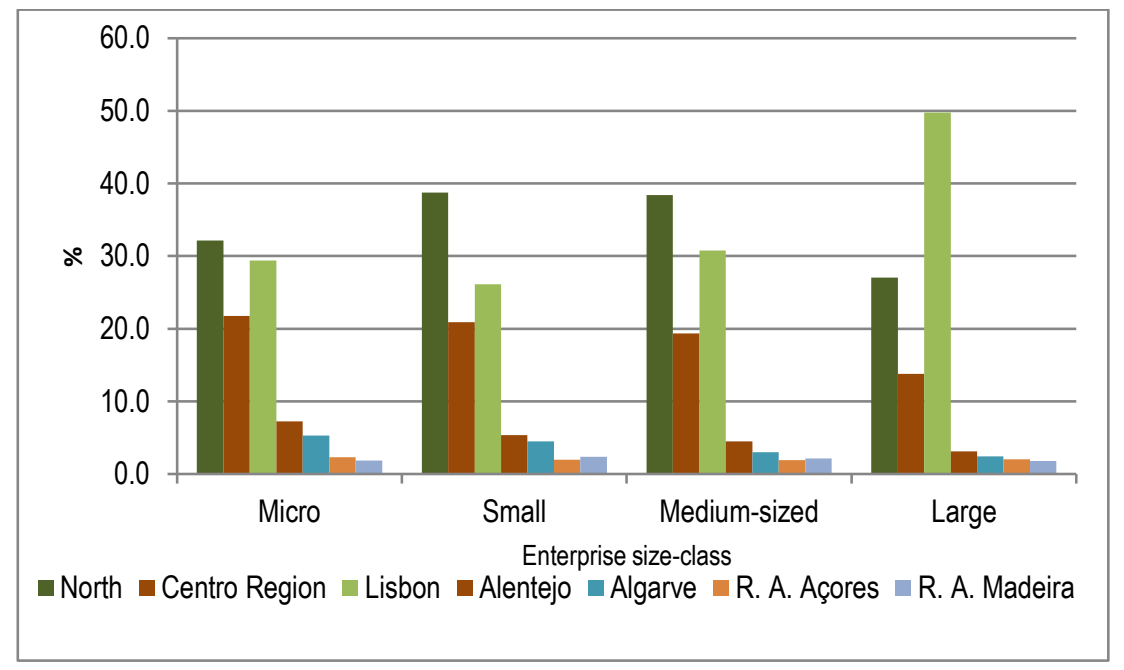

Source: INE, Sistema de Contas Integradas das Empresas, 2015

With regard to small enterprises, the regional breakdown is similar: most of the enterprises are located in the North (38.7\%), with particular relevance to the Greater Porto area (13.1\%), and in the Lisbon region (26.1\%), where the Greater Lisbon sub-region stands out with $21.4 \%$ of the small-sized businesses.

The medium-sized enterprises follow a similar pattern in terms of regional breakdown, with $38.4 \%$ of these businesses being in the North and $30.8 \%$ in the Lisbon region, where, once again, the Greater Lisbon sub-region registers a particularly high figure $(26.5 \%)$.

Finally, the large firms, which have a different regional breakdown since $49.8 \%$ of them are located in the Lisbon region, particularly, yet again, in the Greater Lisbon sub-region, which houses $45.3 \%$ of these firms. It is clear that the North, with $27.1 \%$, has a lower number of large firms and the Greater Porto sub-region, with $13.3 \%$, contrasts sharply with the Greater Lisbon sub-region, where, as mentioned above, $45.3 \%$ of the large firms in the country are located.

Table 2. Breakdown of micro, small, medium-sized and large enterprises of the business sector by NUT II and III in 2015 (\% in columns)

\begin{tabular}{|c|c|c|c|c|c|c|c|c|}
\hline & SMEs & & & & & & & \\
\hline & Micro & & Small & & Medium-sized & Total SMEs & Large & Total \\
\hline Region & $\mathrm{n}$ & $\%$ & $\mathrm{n}$ & $\%$ & $\begin{array}{l}\mathrm{n} \\
\end{array}$ & n $\quad \%$ & $\mathrm{n} \quad \%$ & $n$ \\
\hline
\end{tabular}




\begin{tabular}{lllllll|ll|lll}
\hline North of Portugal & 342810 & $\mathbf{3 2 , 2}$ & 15263 & $\mathbf{3 8 , 7}$ & 2166 & $\mathbf{3 8 , 4}$ & 360239 & 32,4 & 243 & $\mathbf{2 7 , 1}$ & 360482 \\
\hline Minho-Lima & 22789 & 2,1 & 806 & 2,0 & 82 & 1,5 & 23677 & 2,1 & 13 & 1,4 & 23690 \\
\hline Cávado & 38743 & 3,6 & 1961 & 5,0 & 272 & 4,8 & 40976 & 3,7 & 21 & 2,3 & 40997 \\
\hline Ave & 42075 & 3,9 & 2499 & 6,3 & 411 & 7,3 & 44985 & 4,0 & 45 & 5,0 & 45030 \\
\hline Greater Porto & 134516 & 12,6 & 5147 & 13,1 & 691 & 12,3 & 140354 & 12,6 & 119 & 13,3 & 140473 \\
\hline Tâmega & 39728 & 3,7 & 2584 & 6,6 & 424 & 7,5 & 42736 & 3,8 & 14 & 1,6 & 42750 \\
\hline Entre Douro e Vouga & 27117 & 2,5 & 1389 & 3,5 & 218 & 3,9 & 28724 & 2,6 & 24 & 2,7 & 28748 \\
\hline Douro & 18613 & 1,7 & 464 & 1,2 & 44 & 0,8 & 19121 & 1,7 & 3 & 0,3 & 19124 \\
\hline Alto Trás-os-Montes & 19229 & 1,8 & 413 & 1,0 & 24 & 0,4 & 19666 & 1,8 & 4 & 0,4 & 19670 \\
\hline Centro Region & 231819 & $\mathbf{2 1 , 7}$ & 8239 & 20,9 & 1090 & 19,3 & 241148 & 21,7 & 124 & 13,8 & 241272 \\
\hline Lisbon & 313061 & $\mathbf{2 9 , 4}$ & 10299 & $\mathbf{2 6 , 1}$ & 1734 & $\mathbf{3 0 , 8}$ & 325094 & 29,3 & 447 & $\mathbf{4 9 , 8}$ & 325541 \\
\hline Greater Lisbon & 243508 & $\mathbf{2 2 , 8}$ & 8451 & $\mathbf{2 1 , 4}$ & 1493 & $\mathbf{2 6 , 5}$ & 253452 & 22,8 & 407 & $\mathbf{4 5 , 3}$ & 253859 \\
\hline Península de Setúbal & 69553 & 6,5 & 1848 & 4,7 & 241 & 4,3 & 71642 & 6,4 & 40 & 4,5 & 71682 \\
\hline Alentejo & 77349 & 7,3 & 2118 & 5,4 & 252 & 4,5 & 79719 & 7,2 & 28 & 3,1 & 79747 \\
\hline Algarve & 56373 & 5,3 & 1770 & 4,5 & 168 & 3,0 & 58311 & 5,2 & 22 & 2,4 & 58333 \\
\hline Região Autónoma dos Açores & 24724 & 2,3 & 784 & 2,0 & 107 & 1,9 & 25615 & 2,3 & 18 & 2,0 & 25633 \\
\hline Região Autónoma da Madeira & 19929 & 1,9 & 927 & 2,4 & 120 & 2,1 & 20976 & 1,9 & 16 & 1,8 & 20992 \\
\hline
\end{tabular}

Source: INE, Sistema de Contas Integradas das Empresas, 2015

Looking at the full picture of the regional breakdown of Portuguese enterprises, the Alentejo and the Algarve regions also stand out but due to the very low number of businesses. This has, in fact, been considered as a structural feature of the Portuguese business fabric over last 30 years (Freire, 2008, p. 58). Similarly, the business sector on the islands has a very limited number of private enterprises. The breakdown of businesses by region tends, therefore, to follow the country's population concentration and urbanisation profiles.

\section{Family businesses as the dominant business structure}

Family businesses form the basis of the business fabric in most countries and despite the varying degree of importance they have in the different national economies, the fact remains that this type of business is widely present. In fact, family businesses constitute a substantial part of the existing European companies, playing an important role in the dynamism of the European economy as they comprise $60 \%$ of the total number of companies. In Portugal, the situation has more particular features, as discussed above, since the SMEs, especially microenterprises (up to nine workers) are to be found in a wide range of sectors, such as wholesaling and retailing, accommodation and food services, education, human health and social support, fishing, construction, among others. It becomes clear that family businesses have exceptionally diverse internal traits.

The term "family business" may cover distinct realities as regards their size, the professionalisation of management and governance, the organisational structures, including, in some cases, complex subcontracting or outsourcing networks that stimulate emerging added value niche markets or enable the outsourcing of some production chain activities. As such, there may be family businesses that survive merely to keep up the family "business" or, conversely, others that take on the role of major economic agents listed on the stock market, constituting important economic groups.

It is, therefore, understandable that one of the major difficulties lies in reaching a consensus as to what constitutes a family business. In the comparative analysis of various EU countries, the working group that presented the report in 2009 (EU, 2009) opted for a "non-restrictive" and broad definition of family business as "businesses in which a family has influence". Specialised literature on the issue provides over 90 definitions, which reveals how difficult it is to make them operational and ensure comparability both nationally and internationally. 
However, there is some relevant common ground arising from the identification of three key elements: the family, the business and ownership. For Tagiuri \& Davis (1982) there are two features which are helpful for this clarification. One of them consists in using a 3-circle model which highlights that ownership is the central element to distinguish between family and non-family businesses. Secondly, it is considered that the main focus in identifying family businesses should be placed on the quality of the relations between the family and the business, namely on the balance between these two elements rather than on "profit" and "loss" issues that merely serve financial purposes.

In putting forward a definition of family businesses, the Expert Group set up by the European Commission (EU, 2009; Coimbra, 2008) underlines that it is important for it to be both clear and operational. To that end, they consider four elements or dimensions that have to be taken into account when identifying family businesses to distinguish them from non-family businesses. These elements are : 1) the majority of the decisions are made by the founder of the firm, or by the person(s) who obtained the rights to the firm as the natural heir(s), or by an immediate family member; 2) the majority of decisionmaking rights are indirect or direct; 3) at least one family member is formally involved in the governance of the firm; 4) and, finally, registered firms are considered as a family business when the person(s) who founded the firm or their families or descendants possess 25 per cent of the decision-making rights mandated by their share capital.

Two relevant conclusions may be drawn from this definition. The first is that a firm can be considered as a family business even if it has not yet gone through a generational transfer. Various authors maintain there has to be at least one generational transfer for a firm to be regarded as a family business, while this broader definition put forward by the European Union (EU, 2009) does not view it as an exclusive criterion. In fact, there may be firms of different ages that may or not be ready for a generational transfer, which can be planned by means of a family agreement (Costa, Negreira del Rio, Negreira del Rio, 2011; Gersick, et al. 1997). The second conclusion is that self-employed sole proprietors may be included in these family businesses as long as the firm has legal personality, enabling it to be legally transferred.

From this brief literature review on the definition of family businesses ${ }^{1}$ it becomes clear that it is both a complex and challenging issue, requiring more systematic research to pursue certain aspects further.

In fact, family businesses face challenges common to other firms but, above all, they face specific challenges arising from the interconnectedness of the three structural dimensions: ownership (capital), the business (entrepreneurial project) and the family (emotional support and values).

From the outset, there are challenges that stem from the environment in which the firms operate, namely policy makers' low level of awareness of the specificities of family businesses, and their economic and social contribution to a country's development. There are also financial issues connected with inheritance and gift taxes, access to finance without losing control of the firm, and favourable tax treatment of reinvested profits, among others, which impact differently on family and non-family businesses.

Similarly, there are challenges which develop from a family firm's internal matters that merit particular attention. One can point out the lack of attention to/unawareness of the importance of planning business transfers early, which can be a critical aspect for the sustainability of the family business. According to a recent study on the importance of generational transfers in business in Portugal (AEP, 2011), $50 \%$ of the family businesses do not go beyond the second generation and only $20 \%$ reach the third generation, which , to a large extent, explains why only $11 \%$ of the firms questioned considered planning the transfer of the business to be very important. Another issue is how challenging it is to achieve and maintain a balance between the family, ownership and business aspects within the firm. Avoiding overlaps between the different aspects, or minimising areas of contagion between the family and the firm due to interference of conflicts in the day-to-day business takes up time and energy, hampering the success of the business and the quality of the family relationships.

1 Many other authors and issues could be discussed but that would be beyond the scope pf this paper. 
At the same time, several of these family businesses are, to a certain extent, looked down on or have a negative image, resulting generally from perceptions of nepotism or paternalism, which may explain the difficulties they have in attracting and retaining employees, particularly those who are skilled and qualified. The lack of professional careers based on merit, especially in many small-sized family businesses, reinforces those perceptions.

The challenges connected with educational aspects are the ones which may contribute more effectively to a change not only in management practices and professionalisation issues, but also in the organisational cultures and values associated to family businesses. It is thus necessary to promote entrepreneurship education and training for managers and other human resources in family businesses and to effectively coordinate with the education systems so as to ensure there are follow-up processes and concrete action plans.

\section{Roadmap for Portuguese family businesses: aims and expected outputs}

This section presents the project "Roadmap for Portuguese family businesses" [ "Roadmap para Empresas Familiares Portuguesas"], funded within the framework of NORTE-02-0853-FEDER-000018 and headed by the Interdisciplinary Centre of Social Sciences - University of Minho (Portugal) [Centro Interdisciplinar de Ciências Sociais - Universidade do Minho ] in co-promotion with the Portuguese Entrepreneurial Association (AEP) . It is a two-year project (2017-2018) and the partners include expert researchers and scholars, consultants, the main associations (industry, trade and others) registered in the North of Portugal, as well as businessmen and women who will take part in the various actions set out in the project.

The main goal of the project is to ascertain and assess the impact of family businesses of the North of Portugal on the local, national and international economy. Conventional statistical data (namely, economic and financial) will be cross-referenced with more in-depth information, such as governance and generational transfer models, business organisational structures, and human resources profiles (e.g. gender, qualifications, age-groups). This will entail mapping out the family businesses by district, which will enable one to update data on this economic sector and allow for the governmental and economic authorities to acknowledge its impact in financial terms and in terms of job creation.

The expected outputs will be achieved through the following actions:

Action 1: Creating a reliable and comprehensive data base on the types and segments of family businesses in the North of Portugal so as to inform and support the policy decision-making process.

Action 2: Designing an online questionnaire for the different types and segments of family businesses in the North of Portugal, complemented by in-depth interviews to reinforce their economic and social role. This will enable one to update the information on this economic sector and contribute to the acknowledgement of its impact on the economy and society.

Action 3: Disseminating and disclosing information on the project's official website, which will host documents and a variety of initiatives connected with the project, its partners and collaborators. It will contain a wide range of information, such as news, events, statistical analyses, thematic reports and other documents that may substantiate the different family business profiles in the North of Portugal

Action 4: Holding workshops and seminars to disseminate the main findings of the project and to involve and engage family businesses in the planned activities.

All the information collected within the scope of this project will, therefore, be available online on the purposely created official website than can be accessed for free on the LASICS - ICS (University of Minho) platform, allowing researchers to find information to carry out other studies. It should be pointed out that the partnership between the University of Minho and the Portuguese Entrepreneurial Association has made it possible to make the project sustainable beyond its funding period , namely by ensuring the maintenance and continuous update of the official website. It is expected that this will extend the 
knowledge and information about current policies in areas such as the modernisation of the economy, employment and training, as well as about the "quality" of family businesses in the North of Portugal.

\section{Final Remarks}

Family businesses are of crucial importance to Europe. They make a significant contribution to the GDP and employment and tend to be major innovators, with a long term vision, in addition to contributing to the sustainability and development of local communities, constituting essential pillars for the stability of the business fabric.

One should bear in mind that there is no consensual definition of family business, however, one can consider as a family business one in which a family is in charge of appointing the management, and some of the family members have a role and work in the company. Family businesses cut across all economic activity sectors and are not confined to small and medium-sized firms, even though these are the predominant form. It is, nevertheless, worth mentioning that the largest companies in the world are run by families. They have specific challenges which arise from the overlap of the two institutions, Family and Business, which, at the same time, gives it unique features.

The main goal of the ongoing project "Roadmap for Portuguese Family Businesses" is to contribute to a better understanding and assessment of the impact of family businesses of the North of Portugal on the local, national and international economy. This project addresses a major problem that has been identified in Europe and consists in the lack of institutional visibility, particularly of accurate and up-to-date statistics on this sector of the economy.

The aim , therefore, is to strengthen the role of family businesses, especially as regards the potential for technology and knowledge transfer (mainly through start-ups and entrepreneurial activities connected with the R\&D and innovation sectors) and the development of territorial cohesion by their ability to attract and retain human resources locally, underlining the special connection these businesses establish with local communities and the role they play in ensuring stability in the long term.

\section{References}

[1] AEP (Portuguese Entrepreneurial Association) (2011). Livro Branco da Sucessão Empresarial.O desafio da sucessão empresarial em Portugal, Associação Empresarial de Portugal.

[2] Coimbra, A. (2008). Overview of Family Business Relevant Issues - Country Fiche Portugal, In the framework of the Overview of Family-Business-Relevant Issues, KMU Forschung Austria, Austria Institute for SME Research, Available online at: http://www.pedz.uni-mannheim.de/daten/edz$\mathrm{h} / \mathrm{gdb} / 08 /$ familybusines_country_fiche_portugal_en.pdf

[3] Costa, A.N.; Del Rio, F.; Del Rio, J. (2011).50 perguntas essenciais sobre empresas familiares, Vida Económica.

[4] Couto, Ana Isabel (2013). As Pequenas e Médias Empresas e os seus Empresários: Diversidade de Contextos e de Percursos de Empreendedorismo em Portugal. (PhD thesis). Lisboa, ISCTE-IUL.

[5] European Commission (2009). Final Report of the Expert Group - Overview of Family-Business-Relevant Issues: Research, Networks, Policy Measures and Existing Studies, Directorate-Generale for Entreprise and Industry, Available online at: http://ec.europa.eu/entreprise/policies/sms/index_en.htm)

[6] Freire, João (2008). Economia e sociedade. Contributos para uma sociologia da vida económica em Portugal na viragem do século. Oeiras: Celta Editora.

[7] Gersick, K. E.; Davis, J. A.; Hapton, Mc. M.; Lansberg, I. (1997). Generation to Generation - Life Cycles of the Family Business, Harvard Business School Press.

[8] Guerreiro, Maria das Dores (1996). Famílias na actividade empresarial. PME em Portugal. Oeiras: Celta Editora.

[9] Guerreiro, Maria das Dores (coord.), Elsa Pegado, Nuno Rodrigues e Sandra Palma Saleiro (2000). Relações sócio-laborais em micro e pequenas empresas. Lisboa: Observatório do Emprego e Formação Profissional. 
[10] Tagiuri, R.; Davis, J.A. (1982).Bivalent a tributes of the family firm. Working paper, Havard Business School, Cambridge.

[11] Ussman, A.M. (2004). Empresas Familiares, Edições Sílabo. 